\title{
Methods of Increasing the Intensity of Innovative Development of the Higher Education Based on the Interaction of the Scientific and Education Spaces: The Managerial Aspect
}

\author{
Aleksandr Petrovich Zhabin \\ Professor of the Department of Management, Doctor of Economics, President of the Samara State University of Economics; \\ Samara State University of Economics, Russian Federation, Samara \\ Maria Olegovna Suraeva
}

Professor of the Department of Management, Doctor of Economics, Samara State University of Economics Russian Federation, Samara, 141 Sovetskoy Armii Street, Samara, 443090, Russian Federation; E-mail: panda63d@mail.ru

\section{Rustam Idrisovich Khansevyarov}

Professor of the Department of Management, Doctor of Economics, Samara State University of Economics Russian Federation, Samara, 141 Sovetskoy Armii Street, Samara, 443090, Russian Federation; E-mail: panda63d@mail.ru

Doi:10.5901/mjss.2015.v6n5s4p249

\section{Abstract}

The crisis of higher education in Russia is a particular manifestation of the systemic crisis of the country, related to the fact that the existing paradigm of the higher school, established in the industrial era, no longer meets the requirements of the postindustrial labor market. Representations of the educational services meeting the post-industrial paradigm of higher education allow creating a model of the "university environment." This model shows that at the low efficiency of direct, i.e. classical education, the determining factor is the factor of interpersonal communication. This allows us to state that in the Russian conditions, the result achievement should be provided by modifying the basic paradigm, rather than investing financial and/or other resources. The article discusses the prerequisites and problems of the higher education reform in Russia and formulates necessary directions and methodological support for further development of higher education in the conditions of formation of an innovative economy.

Keywords: innovation, management, higher school, management tools, university environment.

\section{Introduction}

\subsection{Prerequisites for the increase of intensity of the innovative development of higher education}

The existing tools of science and education management are largely out of date, because they meet the needs of the industrial era that is coming to its end.

It is therefore necessary to provide creation of new tools, which are a set of information technologies that provide for the appearance of a new type of specialists, able to flexibly readjust in a rapidly transforming market. This, in turn, requires a shift in emphasis from the concept of "competence" to the concept of "creativity" in the process of specialist's training.

Management tools are designed to maximize the use of the factor of interpersonal communication in the process of specialist's training, as well as the factor of increasing motivation for self-learning by the fullest possible integration of the learning process and participation in the research of both fundamental and applied nature.

The importance of the factor of interpersonal communication illustrates the well-known fact-in previous decades, the younger generation acquired the skills in operating computers and other information systems mainly through mutual exchange of information.

In modern literature, it is interpreted through the training capability of the environment.

The learning environment is planned to be created within the framework of a scientific and education innovation cluster that will simultaneously solve the problems of training a new type of specialists (creative management), generating innovations, and putting them into practice. 
Simultaneously, the innovation cluster will provide for the manufacture of high technology products in the Russian Federation and their marketing. The innovation cluster to be formed is a flexible system of start-ups built so that the failure of one of the companies will be offset by benefits gained from others. The created companies are united with common information systems, encouraging the exchange of ideas and proposals for the solution of particular tasks.

Creating an innovative cluster of the proposed type will allow will allow practicing the creative management techniques aimed at managing the scientific and educational space on a region or country scale.

The creative management theory, the purpose of which is to find the optimal parameters of the innovation cluster, their number and optimal degree of relatedness to each other, will serve as the basis for such methods.

\section{Objectives, Methodology, and Research Design}

In accordance with the above, the goal is the development of information methods of management of the research and education space, meeting the conditions of the post-industrial era, as well as their implementation through the establishment of a scientific and education innovation cluster using the methods of the new theory of creative management.

On this basis, the consistent theory of stimulation of the research and improvement of the quality of education based on the management of the information environment connectivity, including the promotion of interpersonal communication, was developed.

This theory for the first time allowed to quantify the interpretation of such a phenomenon as the "university environment," which can take over many of the functions of "direct education" (classroom training, etc.) through the use of self-organizing processes.

The theory allows for performing quantitative predictions. Over the past few years, mass media of the CIS states have repeatedly criticized the state of affairs prevailing in the field of higher education in the former Soviet Union. In particular, in Russia, there was particularly acute criticism of the system of admission of students to higher education institutions (based on the unified state exam).

It must be recognized that higher education in the post-Soviet space does not fully meet the demands and expectations of the society. However, it is not only associated with certain disadvantages of the schemes of the process control in the education space.

The crisis in fact is of large-scale nature, and one of its main reasons is the inconsistence of the structure of higher education, which historically formed in the early days of the industrial age, and the realities of the society of the postindustrial era.

There is no need to prove that higher education is one of the most important institutions of the modern society (or at least should be so).

Formulating the concept of higher education is only justified when the said concept will answer the question about the short- and long-term goals (revised in terms of the public interest) of this institution as a whole, which in turn will require considering the fundamental transformations that the civilization has undergone for the last two decades.

It is necessary to stress that the question is far from trivial.

In a somewhat simplified form, the inconsistence of the industrial high school and the post-industrial labor market can be explained as follows. The post-industrial market is characterized, in particular, by a rapid change in the nature of not only the goods and services provided in it, but also the rapid change of its structure, and the speed of these changes is so great that we can talk about the transition from quantity to quality (Dezhina, 2008; Dezhina, 2003; Siow, 2000).

While earlier the higher school could respond to the emergence of a new technology (or innovations) in a traditional way (through the introduction of a new major and/or specialization), now that path leads to a dead end. The narrow scope of activities become obsolete and/or transform much faster than the maximum attainable reaction rate of the higher school, which is defined by the period of student education in the respective specialization (Kisilev, 2003).

There are a number of reasons speaking of the inconsistence of the industrial higher school and the post-industrial labor market (Lebedeva and Tatarko, 2011). In particular, for any country, there is a critical value of the total number of taught specializations. Their excessive number makes the deterioration of the education quality irreversible due to objective reasons, since such factors as intraprofessional competition, formation of the corresponding segment of the expert community, etc. cease to be.

It is obvious that the maximum possible number of taught specializations depends, inter alia, on the population of the state, which is an additional factor contributing to the crisis addressed.

Another factor is the objectively multidisciplinary nature of any innovations (for more than half a century, all major discoveries and financially successful innovations have been made on the intersection of science, often natural and 
human (Monastyrnyi, 2006).

It is principally impossible to foresee the combination of skills required creating such innovations, and that is why the higher school of the industrial age de facto remains sidelined from this process.

Multidisciplinarity is by definition contrary to the very paradigm of the higher school of the industrial age.

Obviously, it makes no sense to develop concepts based on the administrative counteraction to objective processes.

There is only one way-as much as possible to take into account the peculiarities of the formation of the postindustrial labor market and act in an appropriate paradigm.

In practice, this means that the current focus on the division of areas of training (and therefore, the exaggerated focus on such characteristics of a specialist as "competence") ceases to meet the imperatives.

Moreover, an innovation economy, in principle, cannot make "competence" the cornerstone, since any major innovation is the incompetence by definition.

The emphasis, obviously, should be shifted to "creativity" (in the sense of maximizing the development and utilization of creativity), and the ability to self-training, including skills in handling diverse sources of information, their critical analysis and creative rethinking, should be considered as the main skill of any specialist.

We need to highlight that if the vast majority of university graduates in reality get the skills that are in demand due to self-education (due to employment not related to the specialization), and this trend is determined by the fundamental objective reasons, we must not break this trend, but use, guide, and regulate it.

Accordingly, the higher school of the post-industrial era has to focus not so much on the specialist graduation (although some of their categories still remain popular), but on the preparation of a thinking person, able to easily adapt to the changing circumstances and able to "live" in the supersaturated information environment.

Measures taken recently by the Higher Attestation Commission of the Russian Federation regarding the changes of the requirements for the training of the highest qualified personnel meet the needs of gradual transition to the concept of the post-industrial higher school.

An example of such measures is the sharp tightening of the requirements for the level of scientific papers submitted for publication in the course of preparing dissertations.

However, all these efforts have not led to systemic changes in this field. It is also associated with both the objective factors that are common to all countries of the world and with a few factors.

The objective reasons include, first of all, the fall of the prestige of science as a social institution as a result of a number of crises in the world of science itself.

It must be stressed that the existing paradigms to stimulate and control research activities were also formed in the industrial era. Appropriate tools for the post-industrial society are still at the formation stage-they are actively searched for worldwide.

As a result, over the past decades, the effectiveness of performed research falls in Russia.

One reason for the fall of the effectiveness of scientific research is the crisis of short innovations manifested in reorienting most of the research groups (especially in the core countries of the global economic system) to getting immediate return in financial terms. This has led to a growing gap between the applied and basic research.

Herewith, the fundamental knowledge that has been left over from the previous generation and serving as a basis for the applied research has turned out to be almost completely depleted.

To summarize the above, we can argue that the attempts to stimulate the university research and science focusing only on the criteria of cost-effectiveness are doomed to failure.

The market of applied developments promising in terms of commercialization continuously shrinks worldwide (Shatok, 2006); the competition in the market gets tougher (the short innovation crisis has hit primarily the United States that seek to dampen its effects by means of the "staffing vacuum cleaner").

In these circumstances, it is necessary to revise the viewpoint of the institutional function of the university research and science.

More precisely, it is an essential tool for training young specialists that are to be involved in the scientific activities. This is the view of the institutional role of the university research and science that is to become dominant in modern conditions when, as noted above, the emphasis should shift from "competence" to "creativity."

In today's oversaturated information environment, it is much more important to organize the structure of thinking of a graduate, so that he could learn by himself, and to instill in him the skills of scientific and technical creativity.

In one form or another, this thesis is recognized by virtually all authors who speak on the subject under discussion.

The difficulties are associated with the implementation of this approach, i.e. the key term when discussing the university research and science becomes the phrase "real research." 
If we remove the criterion of economic efficiency, it becomes difficult to assess the feasibility of the implementation of certain research works in general.

In other words, it is necessary to articulate a non-economic criterion allowing to control the quality of the scientific work performed at universities.

In a simplified form, it can be formulated as "matching the world level of research."

As noted above, the requirement was set-to publish at least one scientific work in a journal with a high impact factor during the dissertation preparation.

This very modest step in terms of the concept of formation of the post-industrial higher school caused latent resistance of the conservative part of the education community.

If we do not set the bar high enough, the university research and science (especially with the weakening economic criteria) will inevitably become profaned.

Unfortunately, we have to face the first stage of this process-individual universities replace real research with formal reporting.

This particularly concerns Masters' degree programs-the vast majority of articles published by undergraduates, at best, are literature reviews compiled from network sources.

Here, both the society and the institutions responsible for the management of the processes taking place in the educational space face yet another fundamental problem posed by the formation of the post-industrial era, which can be called the loss of control crisis.

If the system under control goes through a certain threshold of complexity, the distortions of the control signals reach a critical value.

Simply speaking, each element of the chain, by which the order is transmitted, makes small distortions in the transmitted signal, and when there are too many of such units, the control is lost.

This is the reason why in the countries of the world economic system, such concepts as "Project Management" are recognized, which assume not detailed (administrative), but macroscopic (framework) regulation.

With this approach, the governing body denies interference in the activities of the subordinate systems, setting for them only certain framework restrictions and controlling only the result of the process, but not the process itself. It is here where the prerequisites for the unusually broad freedom are, the freedom that is enjoyed by universities in the core countries of the world economic system.

With regard to the conditions of the Russian Federation, this means that such conditions of functioning of universities are to be found, in which the departments would be interested themselves in graduating world-level personnel. Otherwise, the controlling organizations will not be able to complete their task simply because of too large volume of the information being processed.

To force departments to graduate world level personnel is more than just difficult, as in the present conditions, a team of smart enough people will always find a way to circumvent the decisions of the higher authority, just filling out appropriate papers.

It remains only to put them in such conditions that they would be interested in it themselves, and the access to the world level for them would become a vital necessity.

It follows that, for objective reasons of a fundamental nature, the path that is already taken by the HAC of Russia, through increasing requirements for degree seekers is hardly the only possible one. Let us consider a certain idealized example of possible further actions in order to disclose the nature of macroscopic methods of processes regulation in the education space.

At present, the degree of involvement of Russian universities in research remains low. The use of such a resource as the preparation of master's theses, which too often is a mere formality, is at an even lower level. However, this is precisely a resource for innovative development: 10,000 undergraduates-it is 10,000 man-years of work.

However, reducing the requirements for the quality of scientific publications automatically entails profanation of the idea of the master's thesis as a scientific work, and thus will effectively exclude it from the learning process.

Actually, it takes place in practice-theses mostly are compiled texts or quite formal problem solving, not even close to approaching the world level.

The alternative is to prepare just one publication by a team of several masters, which would be of a high level. With all the shortcomings of such a formulation of the problem, it allows solving the main problem. Supervisors will have to be involved in the innovation process in person (the reluctance of a large part of teachers focused only on the learning process to be seriously engaged in science, of course, will cause protests against such an undertaking, but it is a separate issue to address).

Moreover, this approach automatically removes many problems of the education quality control. 
Indeed, if the teacher would be unable to carry out the given amount of scientific work himself, he will be forced to engage undergraduates in the scientific work, i.e. he will select the worthy ones. The chain will be pointed downwardsthe graduating departments will require the general education departments to provide a high level of teaching, etc. Moreover, such negative factors as corruption will be overcome automatically, as soon as it becomes most beneficial (or vital) for the departments to produce a world-class staff.

Of course, the presented scheme is (at least yet) somewhat idealized.

However, it highlights the need for a full-scale research in the theory of management of the educational space. Indeed, until recently, any decisions taken in this field were taken based on expert assessments and other methods reduced to verbal reasoning. Time requires shifting to the construction of precise quantitative theories.

In particular, attempts to "raise the bar" of the level of scientific research at universities will cause a flurry of debate, which will use a variety of arguments, as such measures affect the interests of a very large number of people. The question arises-Is it possible to calculate the specified level, i.e. to solve the problem by calculation?

Thus, the problems of higher education are largely related to the fundamental causes that are not specific to the post-Soviet space. The only answer to the formation of the post-industrial labor market is the revision of the basic paradigm of higher education.

Transformations are inevitable, since they are caused by objective reasons and do not depend on anyone's beliefs and aspirations. Opposition to the objectively emerging trends, as has been repeatedly demonstrated by the history, is a waste of effort.

In this context, we find justified the way based on accurate prediction of the result and, therefore, requiring the construction of mathematical theories of management of the scientific and education space.

The reducing effectiveness and quality of higher education have been marked by many authors (Sobolevskaia and Popov, 2009). There is a view, according to which modern higher education is in crisis, the causes of which are not only linked with the state of affairs in higher education.

According to (Kisilev, 2003), the crisis of modern higher education is one of the manifestations of the systemic crisis of the industrial phase of the civilization development.

Mostly these phenomena are associated with the inertia of mass consciousness. This leads to the determination of the reaction of the public opinion to any reform of higher education by the stereotypes that have formed during the transition period.

In Russia, a lively discussion takes place on how to further reform higher education, which must meet the realities of the transformed society. However, no commonly accepted view of the matter has been formed, which is indicated particularly by mass media materials.

This makes relevant not only the development of measures to counter crises, but also the development of appropriate models that would allow for quantitative verification of various reform strategies and assessment of the likelihood of their success.

\section{Discussion}

\subsection{Methodology of increasing the intensity of innovative development by means of interaction of the scientific and} education spaces

The mathematical model allows evaluating the effectiveness of the higher education based on a set of parameters.

The results of mathematical modeling show that the key factor that can ensure a sharp increase in the quality of higher education is the interpersonal communication among students.

We can note that the need for improvement of the higher education quality is relevant for the vast majority of countries around the world. Moreover, the transition from the industrial to post-industrial society is a definite challenge to the world science (Sobolevskaia and Popov, 2009).

This is due to the fact that higher education built on the industrial paradigm is far from being fully able to meet the demands of the post-industrial labor market (Hammersley, 2000).

The post-industrial labor market is characterized by a fairly rapid emergence of new professions (or substantial transformation of the existing ones), while many of them require diverse skills.

The contemporary higher school, which operates in the industrial paradigm, simply does not have time to establish the corresponding majors. As a result, the training in many professions, especially for the ones emerging on a real-time basis, is actually performed outside of the university programs.

As a consequence, in modern conditions, the value of self-education increases, that is education formed by 
informal institutions or formal institutions not associated with universities.

This model allows us to identify the conditions, under which the university environment becomes crucial. It also allows showing that there are conditions, under which the indicators of the education quality change abruptly at a smooth change of the control parameters.

A quantitative description of the efficiency of educational programs can be developed based on analogies with models describing the promotion of innovations, the most famous among which is Bass' diffusion model (BDM) (Benerjee and Gaston, 2004).

Promoting innovations is determined by two varieties of information impacts on consumers.

One of them is related to the influence of advertising, mass media, etc., and the other-with immediate transmission of information from consumer to consumer («Word-in-mouth»).

Accordingly, the Bass' model leads to an equation containing two terms describing the above-mentioned effects.

$$
\frac{d N}{d t}=\alpha\left(N_{0}-N\right) N+\beta\left(N_{0}-N\right) \text {, }
$$

where coefficients $\alpha$ and $\beta$ characterize the intensity of the information effects of the above types that define the promotion of innovations to the market, $N_{0}$ is the market potential of a particular product or service, $N(t)$ is the number of held users at time $t$. Traditionally, the term proportional to $\alpha$ characterizes the interpersonal impacts, the term proportional to $\beta$-the impact of mass media and advertising.

The analogy between the proposed description of efficiency of educational programs and the models of innovations promotion is as follows. factors.

As in the case of promotion of innovations, the amount of knowledge assimilated by a student is determined by two

One of them is the direct impact of information on the part of teachers in the classroom, and the other is determined by interpersonal communication, mainly informal.

For example, as shown by the results of the survey, the majority of software handling skills was acquired by the students surveyed as a result of interpersonal communication.

In the future, the mutual influence of students on each other during the training will be denoted by the term WordIn-Mouth Education (WIME). This term highlights the analogy between the developed approach and BDM (Kuh, 2001), as well as its modifications.

Formalization of the education model can be built based on ideas about information transitions as follows. "Professional level of knowledge" can be viewed as a set of information packets that the student is to learn in order to acquire competence.

Therefore, the diagram presented in Figure 1 may be applied: The student receives the following information packets and his knowledge moves to the next level. It is expected that the transition to the highest level in the schemelevel $K$-conforms to the acquisition of professional competence.

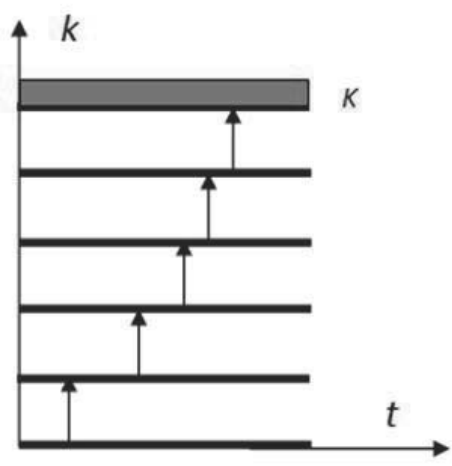

Figure 1. A simplified diagram of the education path

Statistically, the transitions between the levels given in Diagram 1 can be described by the following system of equations. 


$$
\begin{aligned}
& \frac{d N_{0}}{d t}=-N_{0} \sum_{j=1} \alpha_{j 0} N_{j}-\beta_{0} N_{0}+\frac{1}{\tau_{1}} N_{1} \\
& \frac{d N_{k}}{d t}=-\sum_{j=1} \alpha_{j k} N_{j} N_{k}+\sum_{j=1} \alpha_{j k-1} N_{j} N_{k-1}-\beta_{k} N_{k}+\beta_{k-1} N_{k-1}+\frac{N_{k+1}}{\tau_{k+1}}-\frac{N_{k}}{\tau_{k}} \\
& \frac{d N_{K}}{d t}=\sum_{j=1} \alpha_{j, K-1} N_{j} N_{K-1}+\beta_{K-1} N_{K-1}-\frac{1}{\tau_{K}} N_{K}
\end{aligned}
$$

where $N_{k}$ is the number of students who have reached level $k$, coefficients $\alpha_{j k}$ reflect the information impact of interpersonal communication, providing a transition between the levels in the acquisition of additional knowledge, coefficients $\beta$ j describe the efficiency of a direct impact of information during classes.

In equations (2)-(4), it is also taken into account that the student may forget certain information, i.e. in the diagram in Figure 1, there are not only direct but also reverse transitions, which are described by the terms of form $N_{j} / \tau_{j}$.

In equations (5)-(7), the finite duration of the training period is also taken into account-a student can leave the university without gaining the knowledge provided by the program.

System (2)-(4) is sufficiently complex for an analytical study; however, some significant results can be obtained using a simplified model, which contains only 3 levels.

The corresponding simplified system of equations appears as follows.

$$
\begin{aligned}
& \frac{d N_{0}}{d t}=-N_{0}\left(\alpha_{20} N_{2}+\alpha_{10} N_{1}\right)-\beta_{0} N_{0}+\frac{1}{\tau_{1}} N_{1} \\
& \frac{d N_{1}}{d t}=-N_{1}\left(\alpha_{21} N_{2}+\alpha_{11} N_{1}\right)+N_{0}\left(\alpha_{20} N_{0}+\alpha_{10} N_{0}\right)+\beta_{0} N_{0}-\beta_{1} N_{1}-\frac{1}{\tau_{1}} N_{1}+\frac{1}{\tau_{2}} N_{2} \\
& \frac{d N_{2}}{d t}=N_{1}\left(\alpha_{21} N_{2}+\alpha_{11} N_{1}\right)+\beta_{1} N_{1}-\frac{1}{\tau_{2}} N_{2}
\end{aligned}
$$

Summing equations (5)-(7), we can obtain a condition that expresses the constancy of the total number of students at the university.

$$
N_{0}+N_{1}+N_{2}=C
$$

To find the solution, we can use any two equations of system (5)-(7). We select the following:

$$
\begin{aligned}
& \frac{d N_{0}}{d t}=-N_{0}\left(\alpha_{20} N_{2}+\alpha_{10} N_{1}\right)-\beta_{0} N_{0}+\frac{1}{\tau_{1}} N_{1} \\
& \frac{d N_{2}}{d t}=N_{1}\left(\alpha_{21} N_{2}+\alpha_{11} N_{1}\right)+\beta_{1} N_{1}-\frac{1}{\tau_{2}} N_{2}
\end{aligned}
$$

Substituting (8) into the system of equations (9)-(10), we obtain the system of two equations:

$$
\begin{aligned}
& \frac{d N_{0}}{d t}=-N_{0}\left(\alpha_{20} N_{2}+\alpha_{10}\left(C-N_{2}-N_{0}\right)\right)-\beta_{0} N_{0}+\frac{1}{\tau_{1}}\left(C-N_{2}-N_{0}\right) \\
& \frac{d N_{2}}{d t}=q\left(C-N_{2}-N_{0}\right)\left(\alpha_{20} N_{2}+\alpha_{10} N_{1}\left(C-N_{2}-N_{0}\right)\right)+q \beta_{0}\left(C-N_{2}-N_{0}\right)-\frac{1}{\tau_{2}} N_{2}
\end{aligned}
$$

In the derivation of equations (11)-(12), we used the assumption

$$
\left(\alpha_{20}, \alpha_{10}, \beta_{0}\right)=q\left(\alpha_{21}, \alpha_{11}, \beta_{1}\right)
$$

The assumption is justified by the fact that the considered coefficients are determined by the product of the frequency of information impact on its effectiveness. If the frequencies of all information impacts on both levels are the same, i.e., if the "university environment" is rather homogeneous, the recorded relation is true.

To find the equilibrium (steady) states of the system under study, we need to find the stationary points, which can be found from the equations

$$
\begin{aligned}
& N_{0}\left(\alpha_{20} N_{2}+\alpha_{10} N_{1}\right)+\beta_{0} N_{0}-\frac{1}{\tau_{1}} N_{1}=0 \\
& N_{1} q\left(\alpha_{20} N_{2}+\alpha_{10} N_{1}\right)+q_{1} \beta_{0} N_{1}-\frac{1}{\tau_{2}} N_{2}=0
\end{aligned}
$$

Dividing equation (14) by equation (15) term by term, we obtain 
$\frac{N_{1}}{N_{0}}=\frac{\tau_{1}}{q \tau_{2}} \frac{N_{2}}{N_{1}}$

This allows us to determine coefficient $k$, finding which, as will be clear from what follows, is the solution of the system of equations, in accordance with the record

$$
\frac{N_{1}}{N_{0}}=\frac{\tau_{1}}{q \tau_{2}} \frac{N_{2}}{N_{1}}=k
$$

As seen from (17), coefficient $k$ actually shows how many times the share of students who have reached the higher level exceeds the figure related to the lower level.

From (17), we can derive expressions

$$
\begin{aligned}
& N_{1}=k N_{0} \\
& N_{2}=\frac{q \tau_{2}}{\tau_{1}} k^{2} N_{0}=q_{1} k^{2} N_{0}
\end{aligned}
$$

Now, we define the parameter

$$
q_{1}=\frac{\tau_{2}}{\tau_{1}} \frac{\beta_{0}}{\beta_{1}}
$$

The value of parameter $q_{1}$ can be determined from the following arguments. Value

$$
\frac{\beta_{0}}{\tau_{1}}
$$

can be viewed as the product of the frequency of the transition from level " 0 " (according to the scheme in Figure 1) to level "1," which is caused by the direct information impact (teaching in the classroom) on the frequency of the reverse transition, caused by natural loss of information by students. Provided this parameter is equal to one, there is an equilibrium, which means that the number of students who have acquired certain knowledge is equal to the number of students who have forgotten the material. The number of students actually acquiring knowledge in the classroom increases, provided this parameter is greater than one (and vice versa).

Value

$$
\frac{\beta_{1}}{\tau_{2}}
$$

has the same meaning, but with respect to transitions between levels "1" and "2." Parameter (20) is the ratio of these values to each other; therefore, it can be considered as a relative indicator of the efficiency of direct teaching at the first and second stages of the education path.

With parameter (20), we obtain an equation containing parameter $k$ characterizing the relative number of students at different levels

$$
N_{0}^{2}\left(\alpha_{20} q_{1} k^{2}+\alpha_{10} k\right)+\beta_{0} N_{0}-\frac{k}{\tau_{1}} N_{0}=0
$$

(we need to emphasize that record (16) in fact represents one of the equations of the system under consideration; therefore, if it is used, any of the equations of system (14)-(15) can be discarded).

Based on (8), we can immediately write the relation between these values in the form

$$
N_{0}\left(1+k+q_{1} k^{2}\right)=C
$$

Using (23) and (24), we obtain a single equation for the desired parameter $k$

$$
C\left(\alpha_{20} q_{1} k^{2}+\alpha_{10} k\right)+\left(\beta_{0}-\frac{k}{\tau_{1}}\right)\left(1+k+q_{1} k^{2}\right)=0
$$

or

$$
\begin{aligned}
& \text { Or } \\
& C\left(\tau_{1} \alpha_{20} q_{1} k^{2}+\tau_{1} \alpha_{10} k\right)+\left(\tau_{1} \beta_{0}-k\right)\left(1+k+q_{1} k^{2}\right)=0
\end{aligned}
$$

Equation (25) is a canonical equation of the third degree, which can be easily seen if we write

$$
q_{1} k^{3}-\left(\tau_{1} \beta_{0} q_{1}+\tau_{1} \alpha_{20} C q_{1}-1\right) k^{2}-\left(\tau_{1} \beta_{0}+\tau_{1} \alpha_{10} C-1\right) k-\tau_{1} \beta_{0}
$$

We need to note that knowing parameter $\mathrm{k}$ determined from equation (26), we can easily find all other parameters characterizing the system under consideration, in particular, we have

$$
\frac{N_{0}}{C}=\frac{q_{1} k^{2}}{1+k+q_{1} k^{2}}
$$


The nature of the solution of equation (26) for one of the particular cases is illustrated in Figure 2.

These figures demonstrate the dependencies of parameter $k$ on product $\alpha_{20} \tau_{1}$.

This product actually characterizes the intensity of interpersonal communication. More precisely, it can be regarded as the ratio of the frequency of the transition between education levels " 1 " and "2," determined by the mutual training of students, to the frequency of the reverse transition between levels " 1 " and " 0 ."

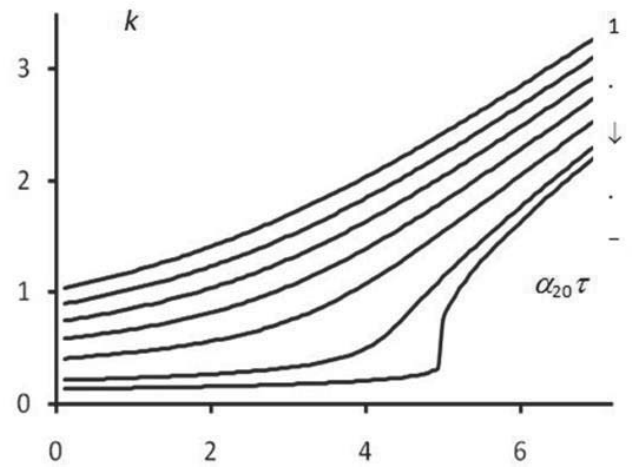

Figure 2. Family of dependencies of coefficient $k$ on $\alpha_{20} \tau_{1}$ for different values of $\beta_{0} \tau_{1} ; q_{1}=0.5, \alpha_{10} \tau_{1}=0.1 ; \beta_{0} \tau_{1}=1.2$ (1), 1.0 (2), 0.8 (3), 0.6 (4), 0.4 (5), 0.2 (6), 0.125 (7)

The curves in these figures correspond to different values of product $\beta_{0} \tau_{1}$ (this product can be considered as the ratio of frequencies of the direct and reverse transitions between education levels " 0 " and "1.")

With relatively large values of parameter $\beta_{0} \tau_{1}$, which characterizes the intensity of direct training, the impact of interpersonal communication, i.e. the "university environment," as such is reduced to a monotonic increase in the proportion of successful students. Non-trivial effects occur with relatively small values of this parameter; the considered curve begins to take the step-like shape.

Completely similar conclusion can be made for the curves obtained for other values of the control parameters.

With further decrease of the value of parameter $\beta_{0} \tau_{1}$, i.e. very poor performance of "direct" training, the factor of interpersonal communication becomes determining. Namely, with such values of parameters, the considered curves become S-shaped.

The existence of S-shaped dependences, obviously, leads to emergence of hysteresis effects.

With the gradual increase in the efficiency of the impact of the "university environment," it initially does not have a significant impact on the quality of education, but later, there is a qualitative leap.

Conversely, if a particular university has formed a specific environment that encourages interpersonal communication ("creative atmosphere"), the deterioration of the quality of education will not be much noticeable, even when such an environment becomes less efficient. However, when a certain threshold is reached, actual disintegration of the environment takes place-the quality of education falls abruptly. Herewith, the threshold values corresponding to the direct and reverse transition do not coincide.

We need to emphasize that the existence of the hysteresis effects is characteristic only for systems with low quality of the direct education (there is every reason to believe that this situation is most typical of Russian universities). Accordingly, in these circumstances, one of the tools to improve the quality of education in general is precisely the creation of a "university environment," which, as shown by the results, is quite able to compensate for the shortcomings of "direct education."

Thus, the "university environment" factor, which is sometimes called the "creative atmosphere," can be quantitatively analyzed based on analogies with the Bass' model describing the dynamics of promoting innovation to the market.

Within the framework of the proposed model, it is necessary to distinguish between "direct" education and education supported by professional interpersonal communication within the university environment.

Stimulation of professional interpersonal communication (the mutual learning factor) in the circumstances of low efficiency of direct education is quite capable of significant improvement and even complete correction of the situation. 
However, in order to make the influence of the university environment on the quality of education noticeable in these circumstances, the intensity of professional interpersonal communication should exceed a certain critical threshold. Upon reaching this threshold, the system shifts to a qualitatively different state characterized by high quality of education.

Therefore, there are all prerequisites for the implementation of the "miracle strategy" based on non-trivial approaches to the management of the scientific and education space and maximum directional stimulation of professional interpersonal communication.

The results show that with the low quality of "direct" education (classroom learning), the key factor that can significantly improve the quality of education becomes the "university environment" as a system of support of interpersonal communication in the professional plane.

\section{Conclusion}

The necessity of forming the paradigm of management of the science and higher education sphere will contribute to the abandonment of the rule of direct administrative control in favor of the macroscopic control schemes based on targeted use of self-organizing processes in social systems.

One of the most effective tools to control the macroscopic scientific and education space may be the creation of a "university environment"-a special communication space, in which learning takes place not only and not so much through formal acquisition of knowledge. Here, the basis will be interpersonal communications driven by a system of innovative projects, the implementation of which directly involves the students.

\section{References}

Benerjee, D., \& Gaston, N. (2004). Labour Market Signaling and Job Turnover. Revisited Labour Economics, 11, 622.

Dezhina, I.G. (2003). Rosssiiskaia nauka kak faktor mirovoi politiki [Russian science as a factor of world science]. Kosmopolis, 2, 43-56 [in Russian].

Dezhina, I.G. (2008). Gosudarstvennoe regulirovanie nauki v Rossii [State control of science in Russia] (pp. 430). Moscow: Magistr [in Russian].

Hammersley, M. (2000). Relevance of Qualitative Research. Oxford Review of Education, Vol. 26, 3,4, 393.

Kisilev, A.F. (2003). Modernizatsiia vysshego obrazovaniia i kliuchevye aspekty effektivnosti podgotovki spetsialistov [Modernization of the higher education and the key aspects of efficiency of specialists training]. Vysshee obrazovanie $v$ Rossii - Higher Education in Russia, 2, 2-8 [in Russian].

Kuh, C. (2001). Learning Productivity at Research Universities. The Journal of Higher Education, 72, 1-28.

Lebedeva, N.M., \& Tatarko, A.N. (2011). Tsennosti i sotsialnyi kapital kak osnova sotsialno-ekonomicheskogo razvitiia [Values and social capital as the basis for socioeconomic development]. Zhurnal institutsionalnykh issledovanii - Journal of Institutional Research, 2(1), 25 [in Russian].

Monastyrnyi, E.A. (2006). Innovatsionnyi klaster [Innovation cluster]. Innovatsii - Innovations, 2, 38-43 [in Russian].

Shatok, M. (2006). Plata za obuchenie v britanskikh vuzakh: nekotorye problemy [Education payment in British Universities: Separate issues]. Ekonomika obrazovaniia - Economy of Education, 5, 69-71 [in Russian].

Siow, A. (2000). Op.Cit. The Journal of Higher Education, 2000, 75.

Sobolevskaia, A.A., \& Popov, A.K. (2009). Postindustrialnaia revoliutsiia v sfere truda [Post-industrial revolution in the labor field] (pp. 205). Moscow: IMEMO RAS. 